https://doi.org/10.46813/2022-137-095

\title{
RADIATION HARDNESS OF POLYSILOXANE-BASED SCINTILLATORS
}

\author{
P.M. Zhmurin ${ }^{1}$, D.A. Yelisieiev ${ }^{1}$, V.D. Alekseev ${ }^{1}$, O.V. Yelisieieva ${ }^{1}$, \\ Yu.O. Hurkalenko', V.Ph. Popov ${ }^{2}$ \\ ${ }^{1}$ Institute of Scintillation Materials, STC “Institute for Single Crystals" \\ National Academy of Sciences of Ukraine, Kharkiv, Ukraine; \\ ${ }^{2}$ National Science Center "Kharkov Institute of Physics and Technology", Kharkiv, Ukraine \\ E-mail: info@isma.kharkov.ua
}

Polysiloxane-based scintillators with different contant of aromatic chromophore groups have been obtained. 2,5-diphenyloxazole and its alkyl derivative were used as activators. The optical and scintillation properties of the obtained polysiloxane scintillators have been studied, and their radiation resistance has been determined. The prospect of using the material in fields with high dose loads is estimated.

PACS: 78.66.Qn; 78.70.Ps; 29.40.Mc; 78.40.Me

\section{INTRODUCTION}

Plastic scintillators (PS) based on polystyrene and polyvinyltoluene are widely used to particles registration in high-energy physics experiments. But with the development of particle accelerator technology, the requirements for the radiation hardness of materials used in the creation of various types of detecting devices have increased. And traditional PSs with a radiation resistance threshold of $1 \ldots 3$ Mrad no longer satisfy the new requirements. The low threshold of radiation hardness of polystyrene and polyvinyltoluenebased PSs is associated with the possibility of the double carbon-carbon bonds formation in the main chain of the macromolecule under the action of irradiation. Various types of polyenes formed in this process dyed the PS's polymer base and act as traps for the excitation energy. In the late 1980s, an alternative to PS based on polystyrene - PS based on polysiloxanes $[1,2]$ was proposed. Since the $\mathrm{Si}-\mathrm{O}$ bond is stronger than the $\mathrm{C}-\mathrm{C}$ bond, the probability of polymer chain damage under the influence of high-energy particles is significantly reduced. But the most important thing is the absence of the possibility of the formation of double bonds, which excludes the possibility of staining the polysiloxane base under the action of radiation. Even in the first experiments devoted to polysiloxane PSs, it was noted that under the action of irradiation with a dose of up to $10 \mathrm{Mrad}$, no significant coloration of the polysiloxane base is observed [3]. Later works presented the results of studying the behavior of polysiloxane scintillators under the action of irradiation with an ion beam [4], where it was also shown that, under the action of high-energy particles in the polysiloxane polymer base, practically no new excitation energy trapping centers are formed.

The main disadvantage of polysiloxanes as PS bases is their mechanical properties. Polymers based on siloxanes are jelly-like materials, which limits theirpractical application area.

However, recently, a group of researchers suggested using polysiloxanes as a scintillating filler of a calorimetric module (the scintillation composition is polymerized directly in the module) [5]. This approach opens up new possibilities for the polysiloxanes use, bypassing the problem of their mechanical properties. Therefore, there is a need for a more detailed study of the properties of polysiloxane scintillators under the influence of various irradiation types.

In addition, when creating radiation-hard scintillation compositions on a polysiloxane base, there is also the problem of finding radiation-resistant activators that can dissolve in sufficient quantities in polysiloxane medium.

This work presents an analysis of the results of irradiation with high-energy electrons of scintillators obtained on the basis of three polysiloxane compositions containing different amounts of aromatic chromophore groups. Scintillators are obtained using traditional and modified activators.

\section{EXPERIMENTAL}

Each polymer composition consisted of a polysiloxane base $\mathrm{A}$, a hardener $\mathrm{B}$, a platinum catalyst [Pt], a POPOP shifter and a corresponding activator (PPO, TBPPO, 3HFTB2). All components, their names, structural formulas and symbols are presented in Table 1.

To obtain samples of polymer compositions, the calculated amount of all components was loaded into glass ampoules (Table 2). The mixture was thoroughly stired, placed in a vacuum desiccator and evacuated for $30 \mathrm{~min}$ at room temperature to remove air bubbles. Then the samples were placed in a heating cabinet and kept for $8 \mathrm{~h}$ at $60^{\circ} \mathrm{C}$.

The excitation and luminescence spectra of the obtained samples were studied at room temperature on a "FluoroMax-4" spectrofluorometer (Horiba Jobin Yvon - Edison).

The device for determining the light yield of the PS consisted of a Hamamatsu R1307 photomultiplier and a LeCrou 2249A charge converter. The PS samples were mounted directly on the surface of the photomultiplier photocathode; optical contact was provided by means of an immersion liquid. Irradiation was carried out with conversion electrons with an energy of $975 \mathrm{keV}$ from a monoenergetic source of the $\mathrm{Bi}-207$ radionuclide. 
Table 1 presence of corresponding bands of activator molecules

Conditional name, structural formula and the chemical name of the polymer composition components

\begin{tabular}{|c|c|c|}
\hline Symbol & Structural formula & Name component \\
\hline A1 & & $\begin{array}{c}\text { Vinyl terminated } \\
\text { (15-17\% diphenylsiloxane)- } \\
\text { dimethylsiloxane copolymer, } \\
1,000-1,500 \mathrm{cSt}\end{array}$ \\
\hline A2 & & $\begin{array}{c}\text { Vinyl terminated } \\
\text { (22-25\% diphenylsiloxane)- } \\
\text { dimethylsiloxane copolymer, } \\
1,000-1,500 \mathrm{cSt}\end{array}$ \\
\hline A3 & & $\begin{array}{c}\text { Vinyl terminated } \\
\text { polyphenyl-methylsiloxane, } \\
300-600 \mathrm{cSt}\end{array}$ \\
\hline B & & $\begin{array}{c}(45-50 \% \text { methylhydrosiloxane) - } \\
\text { phenylmethylsiloxane } \\
\text { copolymer, hydride terminated, } \\
75-110 \mathrm{cSt}\end{array}$ \\
\hline PPO & & 2,5-diphenyl-1,3-oxazole \\
\hline TBPPO & & $\begin{array}{l}\text { 2-phenyl-5-(4-tert-butylphenyl)- } \\
\text { 1,3,4-oxazole }\end{array}$ \\
\hline 3HFTB2 & & $\begin{array}{l}\text { 2-(4-(tert-butyl)phenyl)-6-fluoro- } \\
\text { 3-hydroxy-4H-chromen-4-one }\end{array}$ \\
\hline [Pt] & & $\begin{array}{l}\text { Platinum carbonyl } \\
\text { cyclovinylmethylsiloxane } \\
\text { complex; } 1.85-2.1 \% \mathrm{Pt} \text { in } \\
\text { cyclomethylvinylsiloxanes }\end{array}$ \\
\hline POPOP & & $\begin{array}{l}\text { 1,4-bis(5-phenyl-2- } \\
\text { oxazolyl)benzene }\end{array}$ \\
\hline
\end{tabular}

Table 2

Composition of polysiloxane-based scintillators

\begin{tabular}{|c|c|}
\hline No. & Composition of sample, wt. $\%$ \\
\hline S1 & $\mathrm{A} 1=91.35, \mathrm{~B}=7.5,[\mathrm{Pt}]=0.1, \mathrm{POPOP}=0.05, \mathrm{PPO}=1.0$ \\
\hline S2 & $\mathrm{A} 2=91.35, \mathrm{~B}=7.5,[\mathrm{Pt}]=0.1, \mathrm{POPOP}=0.05, \mathrm{PPO}=1.0$ \\
\hline S3 & $\mathrm{A} 3=91.35, \mathrm{~B}=7.5,[\mathrm{Pt}]=0.1, \mathrm{POPOP}=0.05, \mathrm{PPO}=1.0$ \\
\hline S4 & $\mathrm{A} 3=91.35, \mathrm{~B}=7.5,[\mathrm{Pt}]=0.1, \mathrm{POPOP}=0.05,3 \mathrm{HFTB} 2=1.0$ \\
\hline S5 & $\mathrm{A} 3=90.35, \mathrm{~B}=7.5,[\mathrm{Pt}]=0.1, \mathrm{POPOP}=0.05, \mathrm{TBPPO}=2.0$ \\
\hline
\end{tabular}

The light yield was determined from the position of the amplitude scintillation spectrum peak maximum. The relative light yield of the obtained samples was measured relative to a standard plastic scintillator UPS923A [6].

To determine the radiation hardness, PS samples were irradiated on an LU-10 linear particle accelerator with an electron energy of $9.6 \mathrm{MeV}$ (NSC KIPT NAS Ukraine). The integral radiation dose for all samples was $10 \mathrm{Mrad}$. The light yield of the samples was measured immediately after irradiation.

\section{RESULTS AND DISCUSSION}

Was obtained a number of scintillators containing 1 wt.\% PPO and 0.05 wt. \% POPOP, in polysiloxane bases A1-A3 (samples S1-S3). The luminescence and excitation spectra of the samples clearly show the
(PPO) with maxima at 360 and $379 \mathrm{~nm}$ and a shifter (POPOP) with maxima at 394, 416, and $438 \mathrm{~nm}$ (Fig. 1). The excitation spectra of PPO molecules in polysiloxanes A1-A3 show a broad excitation band through the chromophore phenyl groups of the polymer medium with a maximum at $260 \mathrm{~nm}$. The observed spectra demonstrate the efficiency of the excitation energy transfer from the PS polymer base to the activator and shifter molecules. The excitation and luminescence spectra retained their character and the position of the maxima regardless of the content of phenyl chromophores, i.e. were almost identical for all polysiloxane bases A1-A3.

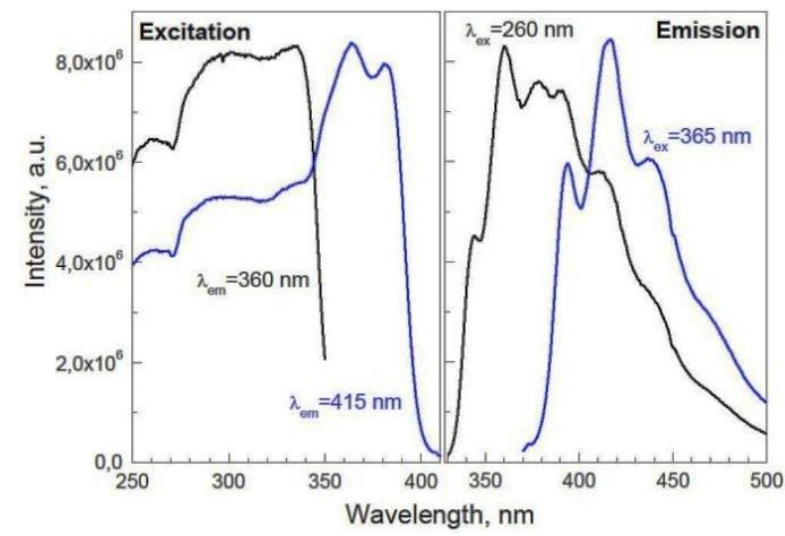

Fig. 1. Excitation and luminescence spectra of PS based on A1-A3 polysiloxanes activated by PPO molecules

It should be noted that the optical spectra of PSs practically did not undergo changes even after irradiation (Fig. 2). This may indicate that under the action of ionizing radiation, the probable destruction of the activator does not lead to the formation of luminescent products with other spectral characteristics.

Of the samples activated by PPO, the best light yield before irradiation was possessed by the samples obtained on a polysiloxane base containing the maximum amount of phenyl chromophore groups - A3, sample S3 (see Table 1, Fig. 2). Such a result is quite expected, since the A3 polymer base contains the largest number of luminescent centers capable of collecting excitation energy from high-energy particles.

Later, this polysiloxane base was used to obtain samples S4 and S5 with other activators.

To improve the solubility of PPO in the polysiloxane base, the molecular structure was modified by introducing a tert-butyl substituent. The introduction of a branched alkyl radical does not significantly affect the spectral-luminescent properties of the activator, but at the same time increases its solubility in non-polar solvents and polymer media - polystyreneand polysiloxanes [7, 8]. An increase in the solubility of the activator made it possible to increase its concentration in the scintillation composition up to $2 \mathrm{wt} . \%$, which should have a favorable effect on its scintillation characteristics (Fig. 3).

An activator with a large Stokes shift is often used to shift the PS luminescence spectrum to longer wavelengths. The most widely used for these purposes is 3-hydroxyflavone (3HF) and its derivatives [9, 10]. 
However, unsubstituted 3HF has low solubility in a low-polarity polysiloxane base.

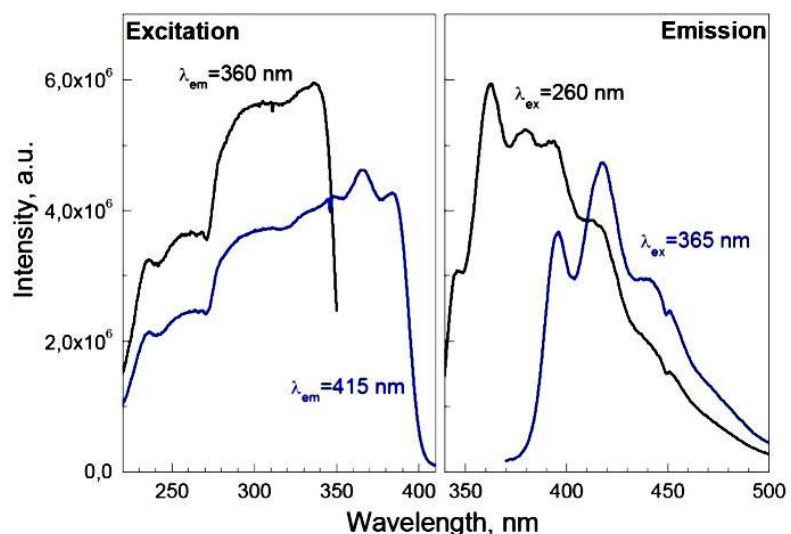

Fig. 2. Excitation and luminescence spectra of PS based on A1-A3 polysiloxanes activated by PPO molecules after irradiation with a dose of $10 \mathrm{Mrad}$

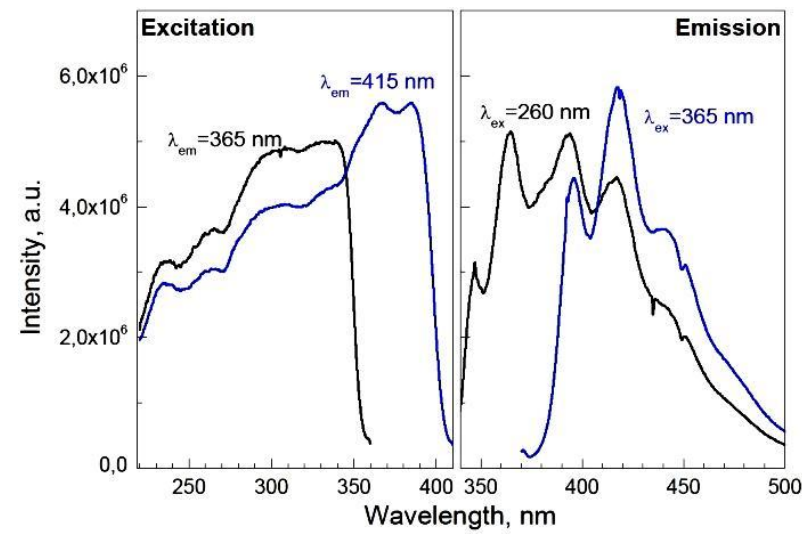

Fig. 3. Excitation and luminescence spectra of PS based on polysiloxane A3, activated by TBPPO molecules

To increase the solubility in the scintillation composition, branched alkyl substituents, for example, tert-butyl [11], are introduced into the 3HF molecule.

In addition, a fluorine atom was introduced into the structure of $3 \mathrm{HF}$ molecules, which, as was shown in [12], increases their own radiation hardness.

The scintillation composition based on polysiloxane A3 and activator 3HFTB2 demonstrates the ability to excite through the phenyl chromophore groups of the polymer base in the region of $260 \mathrm{~nm}$ (Fig. 4). This scintillator has a luminescence band with a maximum at a wavelength of $530 \mathrm{~nm}$, which is typical for $3 \mathrm{HF}$ molecules.

All scintillator samples were irradiated on a linear electron accelerator with an integral dose of $10 \mathrm{Mrad}$. The scintillation characteristics of the samples before and after irradiation are shown in Table 3 and Fig. 5. Table 3 shows the compositions of PSs, their relative light yield before $\left(\mathrm{L}_{0}\right)$ and after irradiation $(\mathrm{L})$, as well as the ratio of light yields after and before irradiation $\left(\mathrm{L} / \mathrm{L}_{0}\right)$, which characterizes the degree of radiation influence on the PSs scintillation characteristics. The value of the light yield half attenuation dose $\left(D_{1 / 2}\right)$ was obtained by extrapolating the available data.

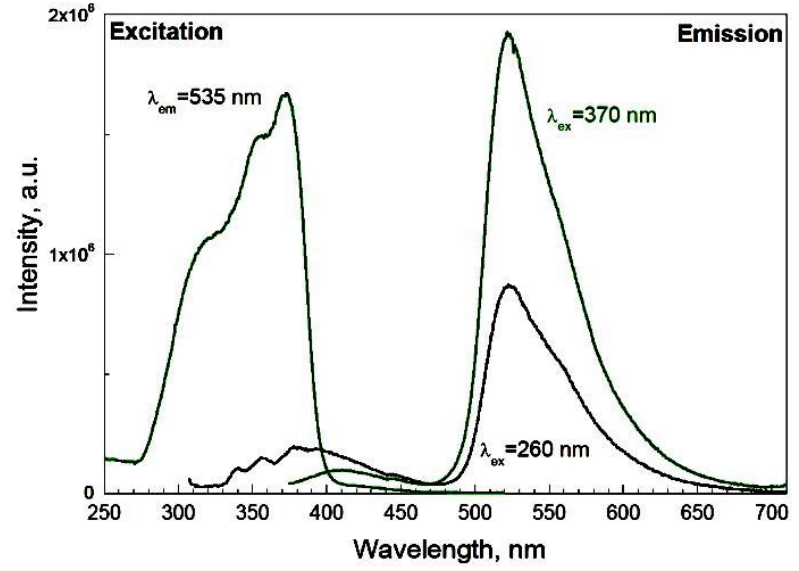

Fig. 4. Excitation and luminescence spectra of PS based on polysiloxane A3, activated by 3 HFTB2 molecules
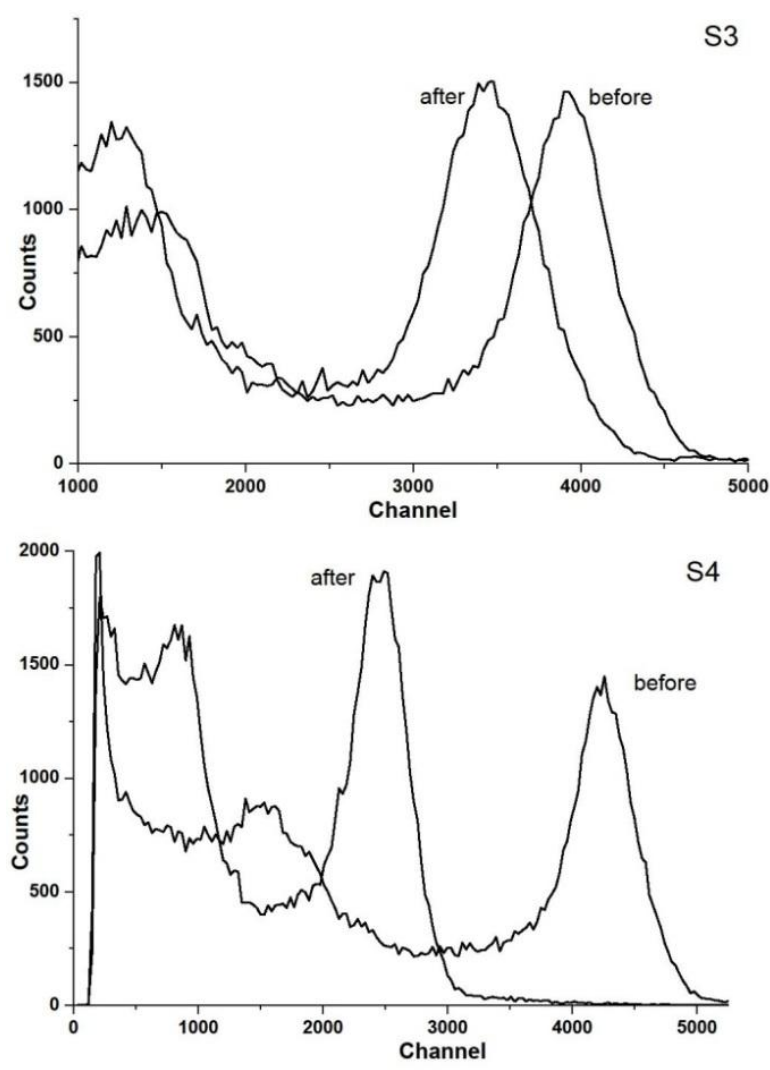

Fig. 5. Scintillation amplitude spectra of PS samples S3 and $S 4$ before and after irradiation with a dose of $10 \mathrm{Mrad}$

Table 3

Scintillation characteristics of the obtained PS before and after irradiation with a dose of $10 \mathrm{Mrad}$

\begin{tabular}{|c|c|c|c|c|}
\hline Sample & $\mathbf{L}_{\mathbf{0}}, \mathbf{\%}$ & $\mathbf{L}, \mathbf{\%}$ & $\mathbf{L}_{\mathbf{L}} \mathbf{0}$ & $\mathbf{D}_{\mathbf{1 / 2}}, \mathbf{M r a d}$ \\
\hline UPS923A & 100 & & & \\
\hline S1 & 45 & 25 & 0.57 & 12.3 \\
\hline S2 & 47 & 37 & 0.79 & 29.8 \\
\hline S3 & 69 & 60 & 0.87 & 51.4 \\
\hline S5 & 74 & 43 & 0.58 & 12.7 \\
\hline S4 & 8 & 5 & 0.64 & 15.2 \\
\hline
\end{tabular}

As expected, in the series of S1-S3 scintillators activated by PPO, the light yield increases with an increase in the content of phenyl chromophores in the composition. 
Of all the samples, the highest initial light yield was observed for PS activated by TBPPO (S4). Modification of the PPO structure with a tert-butyl substituent made it possible to increase its solubility in the polysiloxane base to $2 \mathrm{wt} . \%$, and, as a consequence, improve the conditions for the nonradiative transfer of excitation energy from the polymer base chromophore groups to the activator molecules. So the light yield of the sample with 2 wt.\% TBPPO in A3 (S4) is 7\% higher than that of a scintillator with $1 \mathrm{wt} . \%$ PPO.

A low initial light output was demonstrated by the sample activated by 3 HFTB2. This is partly due to the fact that the maximum luminescence of this activator is in the region of $535 \mathrm{~nm}$, while the maximum sensitivity of the photomultiplier used is located at $420 \mathrm{~nm}$. In the region of $535 \mathrm{~nm}$, the photomultiplier tube sensitivity is 2 times lower than the maximum.

After irradiation with a dose of $10 \mathrm{Mrad}$, the light yield of all PS samples decreased as expected. In the series of PPO activated scintillators, the radiation hardness, like the light yield, increases with an increase of phenyl chromophore groupscontent in the polysiloxane base. In this case, the radiation hardness of a scintillator based on polysiloxane with a maximum content of phenyl chromophores (A3), activated by 1 wt.\% PPO (S3) was about 50 Mrad. As shown by the authors [13], this is due to the fact that the excitation energy of the polymer base is mostly localized on the chromophore groups, therefore it does not go to the activator molecules and polymer base destruction.

Thus, PSs with the A3 basis demonstrate promising results concerning the prospects for their use in fields with a high dose load. But PS activated by TBPPO molecules, which demonstrated the best initial light yield, was significantly degraded as a result of irradiation. Its radiation hardness was only about 13 Mrad. The radiation hardness threshold of polysiloxane-based PS activated by 3 HFTB2 molecules is higher than that of similar PS based on polystyrene [10] and amounted to 15 Mrad. However, the low light output of the obtained polysiloxane composition casts doubt on the advisability of using 3-hydroxyflavone molecules and its derivatives as activators of polysiloxane scintillators.

However, to obtain a complete picture of the behavior of polysiloxane PSs in ionizing radiation fields, it is necessary to study their behavior in more detail, both in a wider range of radiation loads and at different levels of irradiation intensity, in order to study the effect of oxygen diffusion on the stability of activator molecules.

\section{CONCLUSIONS}

Modification of activator molecules makes it possible to vary to a certain extent the scintillation characteristics of polysiloxane-based PSs. The use of a polysiloxane base with a high content of phenyl chromophores makes it possible to obtain PSs whose radiation hardness is an order of magnitude higher than the radiation hardness of polystyrene PSs. This opens up the prospect of their use in radiation fields with a high dose load.

\section{REFERENCES}

1. J.K. Walker, A.R. Katritzky, Z. Degaszfaran. Radiation resistance of polysiloxane based scintillators doped with oxadiazolefluors // Chem. Scr. 1989, v. 29, p. 245.

2. J. Harmon, J. Gaynor, V. Feygelman, J. Walker. Linear polydiorgano-siloxanes as plastic bases for radiation hard scintillators // Nuclear Inst. and Methods in Physics Research, B. 1991, v. 53, p. 309-314.

3. M. Bowen, S. Majewski, D. Pettey, J. Walker, R. Wojcik, C. Zorn. A new radiation-resistant plastic scintillator // IEEE Transactions on Nuclear Science. 1989, v. 36, N 1, p. 562-566.

4. A. Quaranta, S. Carturan, T. Marchi, A. Antonaci, C. Scian, V. Kravchuk, M. Degerlier, F. Gramegna, G. Maggioni. Radiation hardness of polysiloxane scintillators analyzed by ion beam induced luminescence // Nuclear Inst. and Methods in Physics Research, B. 2010, v. 268, p. 3155-3159.

5. F. Acerbi, A. Branca, C. Brizzolari, et al. Polysiloxane-based scintillators for shashlik calorimeters // Nuclear Inst. and Methods in Physics Research, A. 2020, v. 956, p. 163379-163390.

6. V.G. Senchishin, V.N. Lebedev, A.F. Adadurov, I.I. Zalyubovski, A.V. Lebedev, N.P. Khlapova. Radiation resistance investigation of SCSN-81T, BC-408, UPS923A and UPS98RH plastic scintillators // Functional Materials. 2003, v. 10, N 2, p. 281-287.

7. UA Patent 103443, 2013.

8. E. Kowalski, R. Anliker, K. Schmid. Performance Parameters of some New Efficient and highly soluble Solutes for Liquid Scintillators // Molecular Crystals. 1968, v. 4, p. 403-413.

9. A.D. Bross, A. Pla-Dalmau. Radiation effects in intrinsic 3HF scintillator // Nuclear Inst. and Methods in Physics Research, A. 1993, v. 327, p. 337-345.

10. Yu.A. Gurkalenko, P.N. Zhmurin, V.N. Lebedev, V.N. Pereymak, O.V. Svidlo. Radiation-hard plastic scintillators with 3-hydroxyflavone derivatives // Functional Materials. 2016, v. 23, N. 1, p. 40-44.

11. P.N. Zhmurin, Yu.A. Gurkalenko, D.A. Yelisieiev, O.V. Yelisieieva, V.D. Alekseev. 3-Hydroxyflavone tert-butyl fluorine derivative as activator of plastic scintillators // Functional Materials. 2021, v. 28, N 2, p. 241-244.

12. Yu.A. Gurkalenko, P.M. Zhmurin, V.M. Pereymak, D.A. Yelisieiev, O.V. Yelisieieva. Enhance of the polystyrene based plastic scintillator radiation hardness: using fluorine-derivatives of 3-hydroxyflavone // Functional Materials. 2018, v. 25, N 4, p. 670-674.

13. A. Quaranta, S. Carturan, M. Cinausero, T. Marchi, F. Gramegna, M. Degerlier, A. Cemmi, S. Baccaro. Characterization of polysiloxane organic scintillators produced with different phenyl containing blends // Materials Chemistry and Physics. 2013, v. 137, p. 951958. 


\title{
РАДИАЦИОННАЯ СТОЙКОСТЬ СЦИНТИЛЛЯТОРОВ НА ОСНОВЕ ПОЛИСИЛОКСАНОВ
}

\author{
П.Н. Жмурин, Д.А. Елисеев, В.Д. Алексеев, О.В. Елисеева, Ю.А. Гуркаленко, В.Ф. Попов
}

Получены сцинтилляторы на полисилоксановых основах, содержащих в своем составе разное количество ароматических хромофорных групп. В качестве активаторов использованы 2,5-дифенилоксазол и его алкилпроизводное. Изучены оптические и сцинтилляционные свойства полученных полисилоксановых сцинтилляторов, определена их радиационная стойкость. Оценена перспектива использования материала в полях с большими дозовыми нагрузками.

\section{РАДІАЦІЙНА СТІЙКІСТЬ СЦИНТИЛЯТОРІВ НА ОСНОВІ ПОЛІСИЛОКСАНІВ}

П.М. Жмурін, Д.А. Єлісєєв, В.Д. Алексєєв, О.В. Слісєєва, Ю.О. Гуркаленко, В.П. Попов

Отримано сцинтилятори на полісилоксанових основах, що містять у своєму складі різну кількість ароматичних хромофорних груп. Як активатори використано 2,5-дифенілоксазол і його алкілпохідне. Вивчено оптичні та сцинтиляційні властивості отриманих полісилоксанових сцинтиляторів, визначена їх радіаційна стійкість. Оцінено перспективу використання матеріалу в полях 3 великими дозовими навантаженнями. 